\title{
Aucubin suppresses Titanium particles-mediated apoptosis of MC3T3-E1 cells and facilitates osteogenesis by affecting the BMP2/Smads/RunX2 signaling pathway
}

\author{
ZIGUAN ZHU $^{1}$, QINGPING XIE ${ }^{1}$, YAZENG HUANG ${ }^{2}$, SHUIJUN ZHANG ${ }^{2}$ and YU CHEN ${ }^{2}$ \\ Departments of ${ }^{1}$ Hand Surgery and Reconstruction Surgery, and ${ }^{2}$ Orthopaedics, \\ Zhejiang Provincial People's Hospital, People's Hospital of Hangzhou Medical College, \\ Hangzhou, Zhejiang 310014, P.R. China
}

Received October 25, 2017; Accepted March 28, 2018

DOI: $10.3892 / \mathrm{mmr} .2018 .9286$

\begin{abstract}
Aucubin represents an iridoid glucoside separated from multiple Chinese herbs, which has been demonstrated to possess numerous pharmacological activities. In the present study, the aim was to investigate the roles and mechanisms of aucubin in the suppression of mouse MC3T3-E1 osteoblast apoptosis induced by Titanium particles and the promotion of bone formation. MTT assay and flow cytometry were performed to analyze cell viability and apoptosis, respectively. ELISA and para-nitrophenyl phosphate colorimetry were carried out to evaluate the oxidative stress markers and alkaline phosphatase (ALP). Western blotting and reverse transcription-quantitative polymerase chain reaction assays were used to evaluate the associated mRNA and protein expression. The results revealed that aucubin enhanced the cell activity of MC3T3-E1 cells treated with Ti particles. Aucubin suppressed the apoptosis of Ti particles-induced MC3T3-E1 cells and facilitated osteogenesis by affecting the B-cell lymphoma-2 (Bcl-2), Bcl-2 associated X protein, ALP and associated osteogenic factors expression. Aucubin reduced the oxidative stress in $\mathrm{Ti}$ particles-induced MC3T3-E1 cells. In addition, aucubin upregulated the bone morphogenetic protein 2 (BMP2)/Smads/runt related transcription factor 2 (RunX2) pathway in Ti particles-induced MC3T3-E1 cells. In conclusion, the present study confirmed that aucubin suppressed the Ti particles-mediated apoptosis of MC3T3-E1 cells and facilitated osteogenesis by affecting the BMP2/Smads/RunX2 signaling pathway.
\end{abstract}

Correspondence to: Dr Yu Chen, Department of Orthopaedics, Zhejiang Provincial People's Hospital, People's Hospital of Hangzhou Medical College, 158 Shangtang Road, Hangzhou, Zhejiang 310014, P.R. China

E-mail: yuchenmy25@163.com

Key words: aucubin, Titanium particles, MC3T3-E1, bone morphogenetic protein 2, Smads, runt related transcription factor 2

\section{Introduction}

The formation of bone tissues is a complex and orderly dynamic process regulated by bone growth factors of the organism (1). In this process, osteoblasts serve as the main functional cells of osteogenesis to responsible for the synthesis, secretion and mineralization of bone matrix $(2,3)$. Various osteoblast specific genes such as collagen type I (COL I), alkaline phosphatase (ALP), and osteonectin (OPN) express in different periods of the osteoblast differentiation, which further produce the corresponding proteins and secrete to extracellular matrix thereby complete the osteogenesis (4). Moreover, osteocalcin (OCN) and osterix also serve as important factors in the development and process of osteogenesis (5). Previous studies have demonstrated that oxidative stress played a critical role in the progression of osteogenesis (6-8). As a consequence, the study of osteoblast differentiation and other regulatory mechanisms for the repair of bone tissues has important clinical significance.

Titanium (Ti) metal is characterized by better biocompatibility, hardness, inertia, and corrosion resistance, which has been widely used in the design and utilization of artificial arthroplasty (9-11). Ti particles have been proved to inhibit the mesenchymal stem cells (MSCs) osteoblast phenotype expression, bone sialoprotein (BSP) expression, cell proliferation, matrix mineralization and Type I collagen production (12). Furthermore, it also has been demonstrated that Ti particles could induce the apoptosis of MSCs (13). Different sizes of Ti particles and osteoblasts co-culturing could significantly reduce the expression levels of ALP, OPN, and OCN (14). And study has shown that Ti particles with a diameter of 1.5-4.0 $\mu \mathrm{m}$ could markedly suppress the proliferation and functions of osteoblasts (15). Nevertheless, there are few reports in regard to the therapeutic agents and pharmacological mechanisms of Ti particles-mediated osteoblast apoptosis.

Bone morphogenetic proteins (BMPs) are a kind of growth factors that can induce undifferentiated mesenchymal cells to disintegrate into cartilage and bone (16). Smads/runt related transcription factor 2 (RunX2) represents one of the major transduction pathways of BMPs to transmit signals to cells (17). In addition, Smad1/5/8 act as key molecules in the signaling pathway to regulate the target 
genes (18-20). In order to promote the cell differentiation towards osteogenesis, BMPs bind to the promoter regions of corresponding osteoblast-specific ALP and OPN through down-stream transcription factors such as RunX2 and Osterix (21,22). Studies have found that RunX2 was regulated by BMPs via Smads signaling pathway, and RunX2 could upregulate the expression of bone matrix proteins, including OPN and OCN (23-25). Nevertheless, we know little about the mechanisms of BMP2/Smads/RunX2 pathway in the Ti particles-induced osteoblasts apoptosis.

Aucubin represents an iridoid glucoside separated from multiple Chinese herbs involving leaves of Aucuba japonica and Eucommia ulmoides $(26,27)$, which has been demonstrated to possess liver protective activities $(28,29)$, anti-oxidative stress effects $(30,31)$, and anti-inflammatory action (32). It has been well documented the extract of Eucommiae Cortex promoted the osteoblast proliferation and osteogenesis in postmenopausal osteoporosis (33). However, the therapeutic roles and accurate mechanisms of aucubin in the apoptosis of osteoblasts and osteogenesis have not been identified.

In our study, we explored whether aucubin could act as a novel therapeutic agent suppressing the apoptosis of MC3T3-E1 cells induced by $\mathrm{Ti}$ particles and facilitating osteogenesis. Furthermore, it was also fascinating to explore the related apoptosis proteins, osteogenic factors, and signal pathway expression in Ti particles-induced MC3T3-E1 cells treated with different concentration of aucubin.

\section{Materials and methods}

Reagents. The products used in cell culture in our study were purchased from Gibco (Thermo Fisher Scientific, Inc., Waltham, MA, USA). Antibodies and aucubin were purchased from Abcam (Cambridge, UK) and Sigma-Aldrich (Merck KGaA, Darmstadt, Germany), respectively. The Ti particles used in our study were obtained from XiLong Scientific Co., Ltd. (Shenzhen, China). The chemical composition of Ti was (wt\%): Ti 99.3, Fe 0.039, O 0.35, N 0.035, C 0.025, Cl 0.034, H 0.024, and Si 0.0018. Sizing by means of Laser Particle Sizer (OMEC LS-POP III) revealed Ti particles had an average size of less than or equal to $5 \mu \mathrm{m}(95.98 \mathrm{wt} \%$ of Ti particles were in the range 3-4 $\mu \mathrm{m})$.

Cell culture. Mouse MC3T3-E1 osteoblast cell line was obtained from the Cell Bank of Chinese Academy of Sciences. MC3T3-E1 cells were maintained in Dulbecco's modified Eagle's medium (DMEM; Gibco; Thermo Fisher Scientific, Inc.) mixed with $10 \%$ fetal bovine serum (FBS; Gibco; Thermo Fisher Scientific, Inc.) in a $5 \% \mathrm{CO}_{2}$ atmosphere at $37^{\circ} \mathrm{C}$. Afterwards, MC3T3-E1 cells were observed using an inverted microscope for growth status at 24,48 , and $72 \mathrm{~h}$, respectively.

Ti particles treatment. Cells were trypsinized by $0.25 \%$ Trypsin (Beyotime Institute of Biotechnology, Shanghai, China) and seeded into the 6-well plates containing type I collagen. After $24 \mathrm{~h}$, cells were attached to the wall of culture bottles. Culture medium was removed and replaced by $2 \%$ FBS to starve the cells for $16 \mathrm{~h}$. Before the Ti particles treatment, $2 \%$ FBS was replaced by $1 \%$ FBS. Ti particles were dissolved in the phosphate-buffered solution (PBS; XiLong Scientific
Co., Ltd.) and sterilized by autoclaved sterilization. After that, Ti particles ( $\leq 5 \mu \mathrm{m}, 0.1 \mathrm{wt} \%$; XiLong Scientific Co., Ltd.) were added into the cells.

Grouping. Here, five treatment groups were prepared for our study, including control group (cells treated with PBS), Ti group (cells coped with Ti particles), $0.1 \mu \mathrm{M}$ aucubin $+\mathrm{Ti}$ group (cells preprocessed with $0.1 \mu \mathrm{M}$ aucubin for $6 \mathrm{~h}$, and then coped with Ti particles), $1 \mu \mathrm{M}$ aucubin + Ti group (cells preprocessed with $1 \mu \mathrm{M}$ aucubin for $6 \mathrm{~h}$, and then coped with Ti particles), and $10 \mu \mathrm{M}$ aucubin + Ti group (cells preprocessed with $10 \mu \mathrm{M}$ aucubin for $6 \mathrm{~h}$, and then coped with Ti particles).

Cell viability analysis. 3-(4,5-dimethylthiazol-2-yl)-2,5diphenyltetrazolium bromide (MTT) assay was carried out to evaluate the cell vitality of MC3T3-E1 cells. MC3T3-E1 cells at a concentration of $5 \times 10^{3}$ per well were seeded into the 96-well plates and incubated in a $5 \% \mathrm{CO}_{2}$ atmosphere at $37^{\circ} \mathrm{C}$ for $12 \mathrm{~h}$. Afterwards, MC3T3-E1 cells were preprocessed with different concentration of aucubin $(0.1,1$, and $10 \mu \mathrm{M})$ for $6 \mathrm{~h}$. And then, the cells were coped with Ti particles prepared in advance for $12 \mathrm{~h}$. After adding $10 \mu \mathrm{l}$ of MTT solution $(5 \mathrm{mg} / \mathrm{ml}$; Amerco, Reno, NV, USA), MC3T3-E1 cells were maintained at $37^{\circ} \mathrm{C}$ for $6 \mathrm{~h}$. After that, MC3T3-E1 cells were centrifuged at $1,000 \mathrm{x}$ g for $1 \mathrm{~min}$, and the supernatant was removed. Cells were then treated with $100 \mu$ l dimethyl sulfoxide (DMSO; XiLongScientific, Shenzhen, Guangdong, China) under low-speed oscillation for $10 \mathrm{~min}$. The absorbance was detected at $490 \mathrm{~nm}$ wavelength using a microplate reader (BIO-RAD, California, USA). The cell viability and inhibition rate were calculated by the percentage of cell survival compared with control.

Apoptosis assay. Cell apoptosis was assessed by Flow cytometry (FCM). After washing by PBS, MC3T3-E1 cells were trypsinized by $0.25 \%$ Trypsin (Beyotime, Shanghai, China). MC3T3-E1 cells were centrifuged at 1,000 $\mathrm{rpm} / \mathrm{min}$ for $1 \mathrm{~min}$, and the supernatant was removed and the MC3T3-E1 cells for assessment were suspended in the incubation buffer at a density of $1 \times 10^{6}$ cells $/ \mathrm{ml}$. And then cells were maintained with Annexin V-FITC and propidium iodide (PI; XiLong Scientific Co., Ltd.) at room temperature for $15 \mathrm{~min}$ in the dark. After that, cell apoptosis was assessed by FACSCalibur (BD Biosciences, San Diego, CA, USA).

Para-nitrophenyl phosphate (pNPP) colorimetry. Alkaline Phosphatase Colorimetric Assay kit (TE0003; Leagene, Beijing, China) was used in the assessment of ALP activity. The supernatant was collected after lysates of MC3T3-E1 cells centrifuging at $1,000 \mathrm{x} \mathrm{g}$ for $1 \mathrm{~min}$. The collected supernatant and ALP assay buffer were added into the 96-well plates according to the specification. Afterwards, the plates were blended and incubated for $30 \mathrm{~min}$ at $37^{\circ} \mathrm{C}$. Then, stop solution was added into the wells to stop reaction. Finally, the absorbance at $405 \mathrm{~nm}$ was detected by microplate reader (Bio-Rad Laboratories, Inc., Hercules, CA, USA).

Enzyme linked immunosorbent assay (ELISA). The kits used for the assessment of ROS (S0033), MDA (S0131), LDH (C0017), SOD (S0101), and GPx (S0056) in MC3T3-E1 cells 
were obtained from Beyotime Institute of Biotechnology. MC3T3-E1 cells were added into the corresponding wells, and the wells were sealed up by adhesive tape and maintained at $37^{\circ} \mathrm{C}$ for $90 \mathrm{~min}$. And then $100 \mu \mathrm{l}$ biotinylated antibody fluids were added into each well except for the blank wells. Afterwards, wells were sealed by adhesive tape and maintained at $37^{\circ} \mathrm{C}$ for $60 \mathrm{~min}$. Plates were washed by PBS and $100 \mu \mathrm{l}$ enzyme solutions were added into each well. After that, wells were sealed up with adhesive tape and maintained at $37^{\circ} \mathrm{C}$ for $30 \mathrm{~min}$. Chromogenic substrate was added into the wells except for the blank wells. Plates were maintained for $10-15 \mathrm{~min}$ in the dark at $37^{\circ} \mathrm{C}$. Afterwards, stop solution was added into each well, and mixed in 10 min immediately. Finally, the OD450 value was detected by microplate reader (Bio-Rad Laboratories, Inc.).

Western blot analysis. Cell proteins lysates from MC3T3-E1 cells were partitioned by $12 \%$ sodium dodecyl sulfate polyacrylamide gel electrophoresis (SDS-PAGE) and transferred to a PVDF membrane (EMD Millipore, Billerica, MA, USA). Blotting was carried out with spectific antibodies [anti-B-cell lymphoma-2 (Bcl-2) associated $\mathrm{X}$ protein (Bax), 1:5,000 dilution, cat. no. ab32503; Abcam; anti-Bcl-2, 1:1,000 dilution, cat. no. ab692; Abcam; anti-OPN, 1:1,000 dilution, cat. no. ab8448; Abcam; anti-OCN, 1:1,000 dilution, cat. no. ab13418; Abcam; anti-Osterix, 1:1,000 dilution, cat. no. ab94744; Abcam; anti-BMP2, 1:500 dilution, cat. no. ab14933; Abcam; anti-Smad1, 1:1,000 dilution, cat. no. ab33902; Abcam; anti-Smad5, 1:1,000 dilution, cat. no. ab194661; Abcam; anti-Smad8, 1:5,000 dilution, cat. no. ab13723; Abcam; anti-RunX2, 1:500 dilution, cat. no. ab23981; Abcam; anti- $\beta$-actin, 1:1,000 dilution, cat. no. ab8227; Abcam]. After that, horseradish peroxidase-conjugated secondary antibodies (bs-0293M; Bioss, Beijing, China) were added and maintained at room temperature for $1 \mathrm{~h}$. The results were assessed by enhanced chemiluminescent reagents (EMD Millipore) using an ECL system (Amersham Pharmacia, Piscataway, NJ, USA).

Reverse transcription-quantitative polymerase chain reaction $(R T-q P C R)$ analysis. Total RNA was extracted from MC3T3-E1 cells by TRIzol reagent (Thermo Fisher Scientific, Inc.). Afterwards, two microliters of RNA was used for the cDNA synthesis with a first strand cDNA kit (Sigma-Aldrich; Merck KGaA) following the specification. RT-qPCR analysis was carried out using ABI 7500 Thermocycler (Applied Biosystems; Thermo Fisher Scientific, Inc.). PCR cycles were under the following conditions: $10 \mathrm{~min}$ pretreatment at $94^{\circ} \mathrm{C}$, $96^{\circ} \mathrm{C}$ for $15 \mathrm{sec}, 62^{\circ} \mathrm{C}$ for $45 \mathrm{sec}(45 \mathrm{cycles})$, a final extension at $75^{\circ} \mathrm{C}$ for $10 \mathrm{~min}$ and held at $4^{\circ} \mathrm{C}$. $\beta$-actin and GAPDH were utilized as the control of the input RNA level. The primers used in RT-qPCR analysis were designed by Invitrogen (Shanghai, China) and were revealed in Table I.

Statistical analysis. Results in our study were showed as mean \pm SEM of at least three independent experiments. Statistical analysis was performed using IBM SPSS statistical software (version 19; IBM Corp., Armonk, NY, USA). The differences in characteristics between the 2 groups in cell viability analysis, apoptosis assay, pNPP colorimetry, ELISA, western blot analysis, and RT-qPCR analysis were examined by Kruskal-Wallis and Tukey's test. $\mathrm{P}<0.05$ was considered to indicate a statistically significant difference.

\section{Results}

The identification of MC3T3-E1 mouse osteoblast cell line. The morphologic characteristics of MC3T3-E1 mouse osteoblast cell line was observed by inverted microscope at 200 magnification times. As shown in Fig. 1A and B, we found that MC3T3-E1 cells attached to the wall of culture bottle and spread after culturing for 24 and $48 \mathrm{~h}$. However, the confluence state of MC3T3-E1 cells was observed after culturing for $72 \mathrm{~h}$ (Fig. 1C). According to the previous literature, it has been proved that in logarithmic growth phase, MC3T3-E1 cells showed a fibroblastic morphology. The cell grew with a population doubling time. And on day 4 of culture, the cultures reached a confluent monolayer at a density of 5-6x10 $\mathrm{cells} / \mathrm{cm}^{2}$, showing a mosaic appearance (34). Hence, based on our observation of the cultured cells, we confirmed that the cell line was MC3T3-E1 mouse osteoblast.

Aucubin enhanced the cell activity of MC3T3-E1 cells coped with Ti particles. MTT assay data (Fig. 2) revealed that the cell viability of MC3T3-E1 cells treated with Ti particles for $12 \mathrm{~h}(55.86 \pm 5.9 \%)$ was distinctly lower than control $(100 \pm 0 \%)$. However, compared with the MC3T3-E1 cells coped with Ti particles, we found that the cell viability of $\mathrm{Ti}$ particles-induced MC3T3-E1 cells in aucubin preprocessing groups was obviously enhanced, especially in the $10 \mu \mathrm{M}$ aucubin treatment group $(86.96 \pm 4.5 \%)$. These consequences indicated that aucubin could enhance the cell viability of MC3T3-E1 cells suppressed by Ti particles.

Aucubin suppressed the apoptosis of Ti particles-induced MC3T3-E1 cells. As FCM data revealed in Fig. 3, the percentage of apoptosis MC3T3-E1 cell number in Ti group was $20.13 \pm 2.06 \%$, which was markedly higher than control $(6.44 \pm 0.42 \%)$. Nevertheless, after treating with different concentration of aucubin, the apoptosis rate of MC3T3-E1 cells was reduced to $14.71 \pm 1.02,11.15 \pm 0.89$, and $8.94 \pm 0.65 \%$, respectively. These data indicated that aucubin significantly weakened the apoptosis capacity of MC3T3-E1 cells which was enhanced by $\mathrm{Ti}$ particles. In addition, we also studied the apoptosis-associated proteins expression in MC3T3-E1 cells. According to the RT-qPCR and western blot data, we found that the Bax expression in Ti group (6.62 \pm 0.31$)$ was significantly higher than control $(1 \pm 0.05)$, while the Bax expression in Ti particles-induced MC3T3-E1 cells was obviously lessened by aucubin $(3.73 \pm 0.15,2.37 \pm 0.12,1.52 \pm 0.25$; Fig. 4A and B). However, we also found that Ti particles markedly reduced the expression level of Bcl-2 in MC3T3-E1 cells $(0.16 \pm 0.01)$, while aucubin could evidently upregulate the Bcl-2 expression in Ti particles-induced MC3T3-E1 cells $(0.72 \pm 0.02,0.85 \pm 0.04$, and 0.96 \pm 0.04 ; Fig. 4A and B). Based on these consequences, we confirmed that aucubin suppressed the apoptosis of Ti particles-induced MC3T3-E1 cells through regulating the Bax and Bcl-2 expression.

Aucubin reduced the oxidative stress in Ti particles-induced MC3T3-E1 cells. Malondialdehyde (MDA), lactate 
Table I. Sequences of the primers used for reverse transcription-quantitative polymerase chain reaction.

\begin{tabular}{|c|c|c|c|}
\hline Gene & Direction & Sequence $\left(5^{\prime}-3^{\prime}\right)$ & Product (bp) \\
\hline \multirow[t]{2}{*}{ Bax } & Forward & TCTCCGGCGAATTGGAGATG & 253 \\
\hline & Reverse & CTCACGGAGGAAGTCCAGTG & \\
\hline \multirow[t]{2}{*}{$\mathrm{Bcl}-2$} & Forward & TGCGTGAAGGCTTGAGATGT & 201 \\
\hline & Reverse & TCССССТTТССТАGACCCAG & \\
\hline \multirow[t]{2}{*}{ OPN } & Forward & GCCACAAGTTTCACAGCCAC & 371 \\
\hline & Reverse & AAAATGCAGTGGCCGTTTGC & \\
\hline \multirow[t]{2}{*}{$\mathrm{OCN}$} & Forward & GCACACCTAGCAGACACCAT & 320 \\
\hline & Reverse & GGGCAGCACAGGTCCTAAAT & \\
\hline \multirow[t]{2}{*}{ Osterix } & Forward & TGCTATACTCTGGGGGCTCT & 296 \\
\hline & Reverse & ACAAAGCTCAGGGGGAATCG & \\
\hline \multirow[t]{2}{*}{ BMP2 } & Forward & TGAGCAAAGTGCTTGCACAC & 360 \\
\hline & Reverse & AGCCCCCTGGAAGGGATTAT & \\
\hline \multirow[t]{2}{*}{ Smad1 } & Forward & AGTGGGCTTTCATCAGGCTC & 318 \\
\hline & Reverse & TCTACATTTGCAGCCGTCGT & \\
\hline \multirow[t]{2}{*}{ Smad5 } & Forward & TCTGGGAATTTCTTTGCCTTACC & 355 \\
\hline & Reverse & AATTGTTGGCCCAAAGCAGC & \\
\hline \multirow[t]{2}{*}{ Smad8 } & Forward & TAAGTCACGTCGTCAGCCAC & 322 \\
\hline & Reverse & GTGTTTTCCATGTGGGGCAC & \\
\hline \multirow[t]{2}{*}{ RunX2 } & Forward & AGCGGCAGAATGGATGAGTC & 280 \\
\hline & Reverse & ACCAGACAACACCTTTGACG & \\
\hline \multirow[t]{2}{*}{$\beta$-actin } & Forward & GTTACAGGAAGTCCCTCACCC & 194 \\
\hline & Reverse & CAGACCTGGGCCATTCAGAAA & \\
\hline
\end{tabular}

Bcl-2,B-cell lymphoma 2; Bax, Bcl-2-associated X protein; OPN, osteonectin; OCN, osteocalcin; BMP2, bone morphogenetic protein 2; RunX2, runt related transcription factor 2 ; bp, base pairs.

dehydrogenase $(\mathrm{LDH})$, reactive oxygen species (ROS), glutathione peroxidase (GPx), and superoxide dismutase (SOD) represent the most important markers of oxidative stress in cellula. In our investigation, ELISA was carried out to evaluate the levels of oxidative stress markers in MC3T3-E1 cells treated with Ti particles and different concentration of aucubin. According to the results, we found that the $\operatorname{ROS}(18.23 \pm 1.20)$, MDA $(1.56 \pm 0.09)$, and LDH $(129.89 \pm 3.00)$ content in MC3T3-E1 cells treated with Ti particles were markedly higher than control, while aucubin significantly lessened the ROS $(15.63 \pm 1.00,12.03 \pm 0.89$, and $8.99 \pm 0.56), \operatorname{MDA}(1.25 \pm 0.08,1.03 \pm 0.01$, and $0.59 \pm 0.03)$, and $\mathrm{LDH}(112.36 \pm 2.90,108.56 \pm 2.50$, and $85.36 \pm 3.10)$ content in Ti particles-induced MC3T3-E1 cells (Fig. 5A-C). Nevertheless, Ti particles were observed to reduce the SOD $(55.23 \pm 15.37)$ and GPx $(7.96 \pm 0.23)$ activities in MC3T3-E1 cells. After treating with different concentration of aucubin, the SOD $(69.36 \pm 18.45,98.02 \pm 20.30$, and $128.69 \pm 18.36)$ and GPx $(9.89 \pm 0.23,12.23 \pm 0.33$, and $14.52 \pm 0.41)$ activity in $\mathrm{Ti}$ particles-induced MC3T3-E1 cells was distinctly enhanced (Fig. 5D and E). To sum up, we confirmed that aucubin reduced the ROS, MDA, and $\mathrm{LDH}$ content, while enhanced the SOD and GPx activity in Ti particles-induced MC3T3-E1 cells. Due to the modulation of oxidative markers in $\mathrm{Ti}$ particles-induced MC3T3-E1 cells, it was demonstrated that aucubin reduced the oxidative stress in Ti particles-induced MC3T3-E1 cells.
Aubucin facilitated osteogenesis through regulating the related osteogenic factors expression. In order to explore the effects of aucubin in bone formation, we further studied the related osteogenic factors expression in MC3T3-E1 cells coped with Ti particles and aucubin. The pNPP colorimetry data indicated that activity of ALP in MC3T3-E1 cells was markedly reduced by Ti particles $(10.02 \pm 0.23)$, while increases were observed in Ti particles-induced MC3T3-E1 cells treated with aucubin $(28.50 \pm 0.98,35.20 \pm 1.85$, and $45.90 \pm 2.89$; Fig. 5F). Moreover, the mRNA expression levels of OPN $(0.24 \pm 0.05)$, OCN $(0.38 \pm 0.01)$, and Osterix $(0.13 \pm 0.01)$ in MC3T3-E1 cells were significantly decreased by $\mathrm{Ti}$ particles (Fig. 6A). After treating with different concentration of aucubin, the OPN $(0.33 \pm 0.01,0.53 \pm 0.03$, and $0.65 \pm 0.02), \mathrm{OCN}(0.75 \pm 0.03,0.73 \pm 0.03$, and $0.85 \pm 0.04)$, and Osterix $(0.33 \pm 0.01,0.46 \pm 0.02$, and $0.64 \pm 0.03)$ expression in Ti particles-induced MC3T3-E1 cells was markedly enhanced (Fig. 6A). Additionally, the protein expression levels of OPN $(0.14 \pm 0.01 ; 0.21 \pm 0.01,0.33 \pm 0.03$, and $0.51 \pm 0.03)$, OCN $(0.11 \pm 0.01 ; 0.22 \pm 0.01,0.27 \pm 0.02$, and $0.38 \pm 0.02)$, and Osterix $(0.16 \pm 0.01 ; 0.25 \pm 0.01,0.35 \pm 0.02$, and $0.55 \pm 0.02)$ in MC3T3-E1 cells treated with Ti particles and aucubin verified the RT-qPCR results (Fig. 6B). Hence, it was determined that $\mathrm{Ti}$ particles suppressed the OPN, OCN, and Osterix expression in MC3T3-E1 cells, while aucubin strengthened the OPN, OCN, and Osterix expression in Ti particles-induced MC3T3-E1 cells. According to 
A

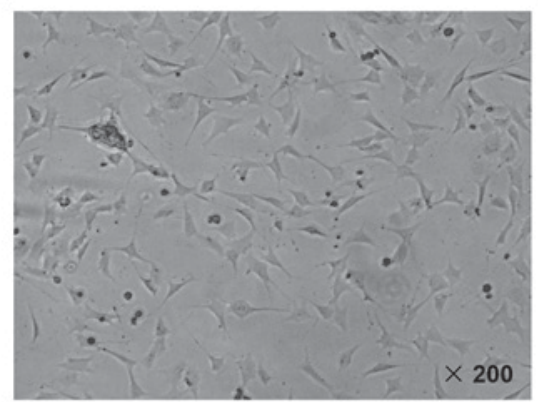

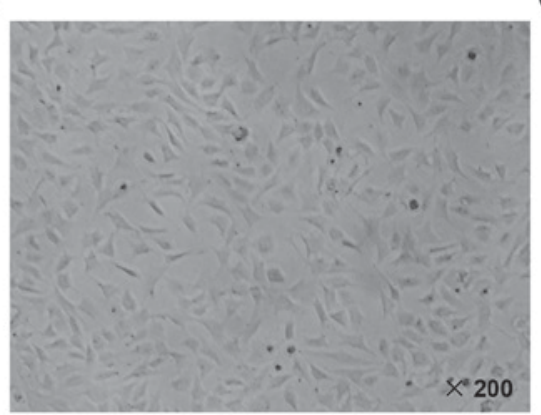

C

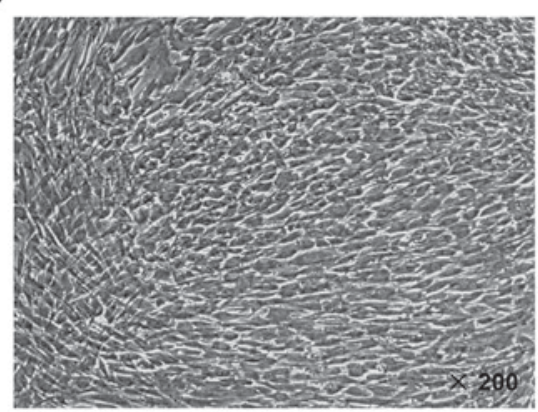

Figure 1. Identification of MC3T3-E1 mouse osteoblast cell line. The MC3T3-E1 cells were observed using an inverted fluorescence microscope at x200 magnification following culture for (A) $24 \mathrm{~h}$, (B) $48 \mathrm{~h}$ and (C) $72 \mathrm{~h}$, respectively.

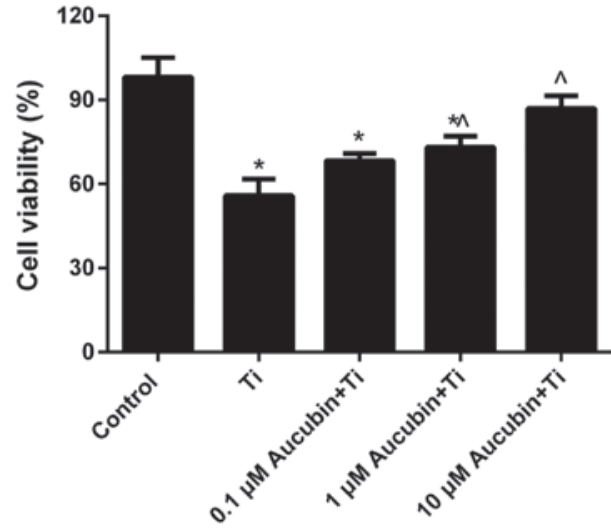

Figure 2. Aucubin enhances the cell viability of Ti particles-induced MC3T3-E1 cells. MC3T3-E1 cells were preprocessed with different concentration of aucubin $(0.1,1$ and $10 \mu \mathrm{M})$ for $6 \mathrm{~h}$ in advance, and then treated with Ti particles ( $\leq 5 \mu \mathrm{m}, 0.1 \mathrm{wt} \%$ ) for $12 \mathrm{~h}$. MTT assay was performed to assess the cell viability of MC3T3-E1 cells. Data are presented as the mean \pm standard error mean $(\mathrm{n}=3)$. ${ }^{*} \mathrm{P}<0.05$ vs. control; ${ }^{\wedge} \mathrm{P}<0.05$ vs. Ti particles. Ti, titanium.

these conclusions, we conjectured that aucubin facilitated osteogenesis through enhancing the activity of ALP and upregulating the osteogenesis-related genes expression.

Aucubin affected the BMP2/Smads/RunX2 pathway. Furthermore, we assessed the BMP2, Smad1/5/8, and RunX2 expression in MC3T3-E1 cells from each group. The RT-qPCR and western blot results indicated that the BMP2 $(0.08 \pm 0.001)$, Smad1 $(0.24 \pm 0.01) / 5(0.02 \pm 0.001) / 8(0.35 \pm 0.001)$, and RunX2 $(0.21 \pm 0.01)$ expression in MC3T3-E1 cells coped with Ti particles were significantly lower than control. However, distinct increases of BMP2 $(0.33 \pm 0.01,0.43 \pm 0.02$, and $0.71 \pm 0.02)$, Smad1 $(0.44 \pm 0.02,0.67 \pm 0.02$, and $0.81 \pm 0.04) / 5(0.54 \pm 0.02,0.80 \pm 0.03$ and $0.85 \pm 0.02) / 8(0.56 \pm 0.02,0.67 \pm 0.03$, and $0.86 \pm 0.04)$, and RunX2 $(0.52 \pm 0.02,0.71 \pm 0.03$, and $0.89 \pm 0.02)$ expression were observed in the Ti particles-induced MC3T3-E1 cells treated with aucubin (Fig. 7A-C). Therefore, it was affirmed that BMP2/Smads/RunX2 pathway could be upregulated by aucubin in MC3T3-E1 cells induced by Ti particles.

\section{Discussion}

In the traditional sense, osteoblasts are mainly derived from the primary cell culture of living tissues, which is closer to the physiological condition of organism (35). However, in vitro culture of primary cells susceptible to extraction conditions, culture environment, and other factors, which might impact the cell proliferation and differentiation of osteoblasts. In addition, different batches of primary cells often unable to maintain the genetic stability (36). Thus, we chose MC3T3-E1 cells as the study object in the current research. MC3T3-E1 cell line was first separated from the newborn C57BL/6 mouse skull bone and established as osteoblasts cell line by a Japanese scholar Kodama in 1981 (34). MC3T3-E1 cell line possesses stable proliferation, infinite cell passage function, and multiple biological characteristics of osteoblasts, involving ALP activity, COLI synthesis, and matrix mineralization. Hence, MC3T3-E1 cells were often used as the cell model in the bone metabolism research $(37,38)$.

Aucubin represents an iridoid glucoside separated from multiple Chinese herbs involving leaves of Aucuba japonica and Eucommia ulmoides, which has been demonstrated to possess numerous pharmacological activities $(26,27)$. It has been reported that the components of Eucommiae Cortex activated the osteoblast and further facilitated osteogenesis (33). Recent study also has proved that the extract of Eucommia ulmoides leaves antagonized $\mathrm{H}_{2} \mathrm{O}_{2}$-induced mouse MC3T3-E1 apoptosis via suppressing the expression of Caspases 3/6/7/9 (39). Up to now, although many studies were in regard to aucubin and osteoblasts, the apoptosis and related mechanisms of Ti particles-induced osteoblasts treated with aucubin is not clear. In our study, it was confirmed that aucubin evidently enhanced the cell activity of Ti particles-induced MC3T3-E1 cells. Hence, we conjectured whether aucubin posesses the functions in the suppression of MC3T3-E1 cell apoptosis. We further evaluated the effect of Ti particles and aucubin on the apoptosis of MC3T3-E1 cells. Experimental data indicated that Ti particles led to high percentage of apoptosis cell number, while aucubin significantly inhibited the apoptosis of Ti particles-induced MC3T3-E1 cells. Furthermore, the apoptosis-associated mechanisms in MC3T3-E1 cells coped with Ti particles and aucubin were investigated. It was revealed that aucubin obviously reduced the Bax expression, while upregulated the Bcl-2 expression in Ti particles-induced MC3T3-E1 cells. Therefore, we could draw the conclusion that aucubin inhibited the Ti particles-mediated apoptosis of MC3T3-E1 cells through regulating the expression levels of Bax and Bcl-2.

Mitochondria play a crucial part in the cell growth and death and possess the function of ROS generation and 

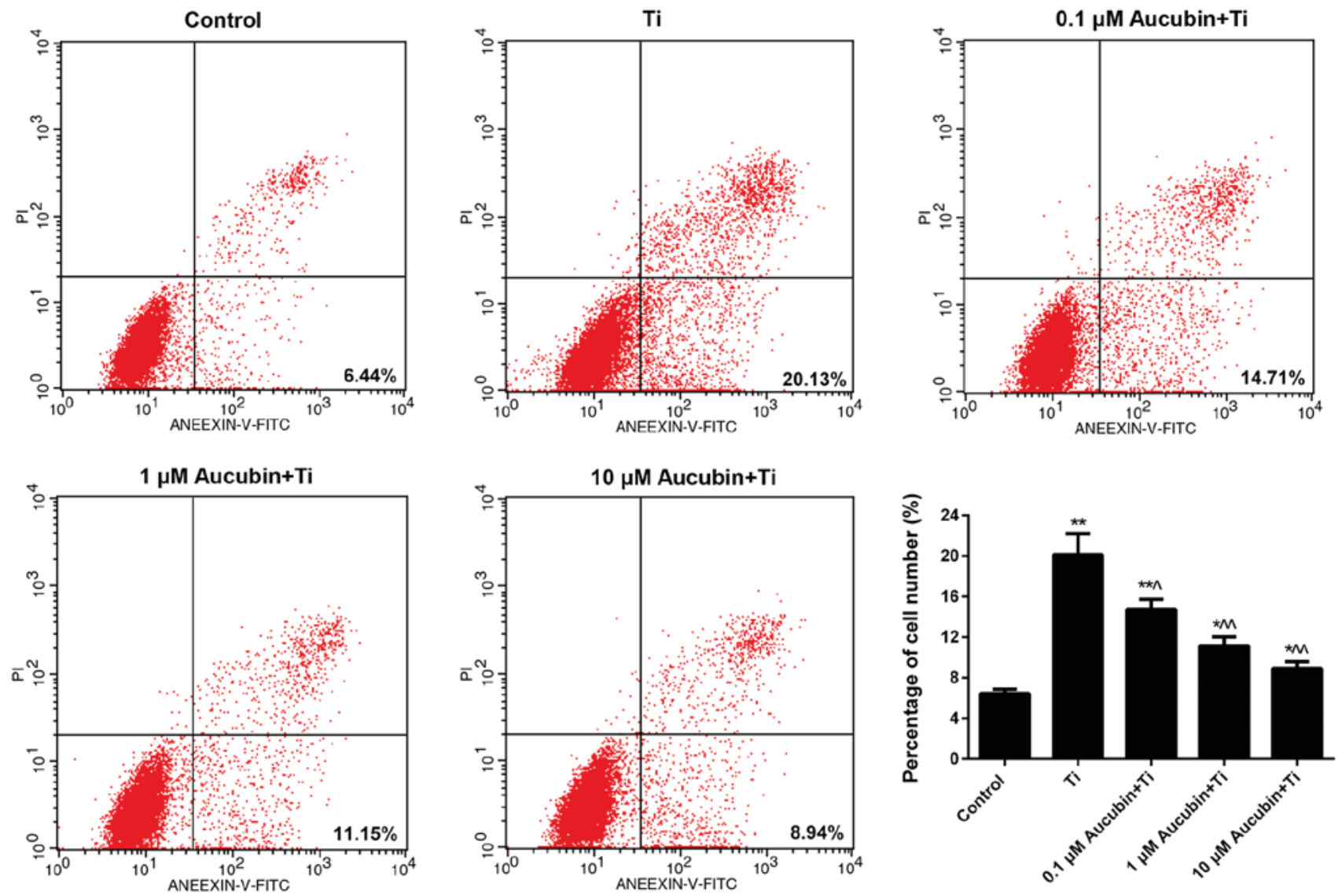

Figure 3. Aucubin reduces the apoptosis of Ti particles-induced MC3T3-E1 cells. MC3T3-E1 cells were preprocessed with different concentration of aucubin $(0.1,1$ and $10 \mu \mathrm{M})$ for $6 \mathrm{~h}$ in advance, and then treated with Ti particles $(\leq 5 \mu \mathrm{m}, 0.1 \mathrm{wt} \%)$ for $12 \mathrm{~h}$. Cell apoptosis was evaluated by flow cytometry. Data are presented as the mean \pm standard error mean $(\mathrm{n}=3)$. ${ }^{*} \mathrm{P}<0.05$ and ${ }^{* *} \mathrm{P}<0.01$ vs. control; ${ }^{\wedge} \mathrm{P}<0.05$ and ${ }^{\wedge \wedge} \mathrm{P}<0.01$ vs. Ti particles. Ti, titanium; FITC, fluorescein isothiocyanate; PI, propidium iodide.

A

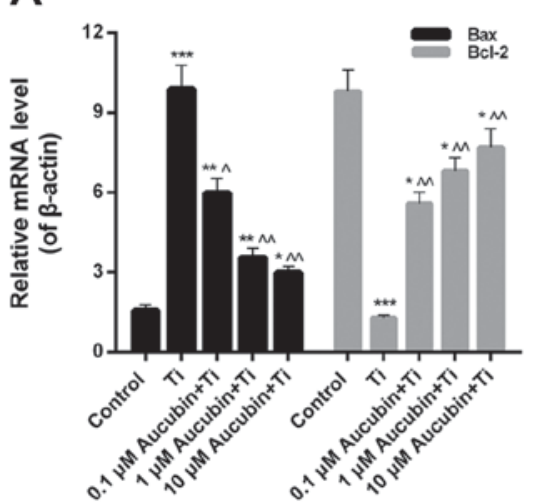

B

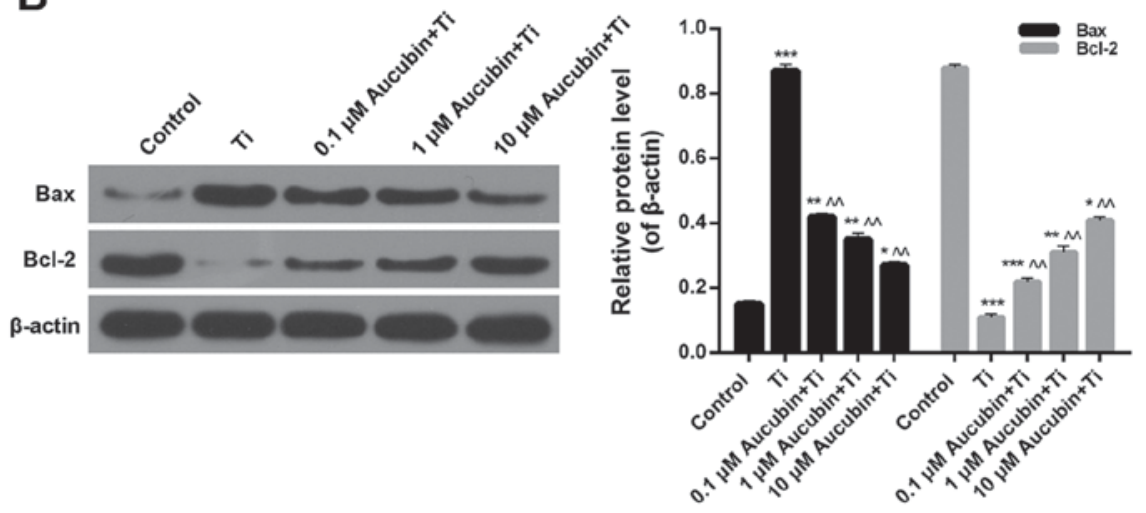

Figure 4. Aucubin regulates the apoptosis-associated genes and proteins expression in Ti particles-induced MC3T3-E1 cells. MC3T3-E1 cells were preprocessed with different concentration of aucubin $(0.1,1$ and $10 \mu \mathrm{M})$ for $6 \mathrm{~h}$ in advance, and then treated with Ti particles $(\leq 5 \mu \mathrm{m}, 0.1 \mathrm{wt} \%)$ for $12 \mathrm{~h}$. (A) Reverse transcription-quantitative polymerase chain reaction and (B) western blot assays were performed to determine Bax and Bcl-2 expression in MC3T3-E1 cells. Data are presented as the mean \pm standard error mean $(\mathrm{n}=3) .{ }^{*} \mathrm{P}<0.05,{ }^{* *} \mathrm{P}<0.01$ and ${ }^{* * *} \mathrm{P}<0.001$ vs. control; ${ }^{\wedge} \mathrm{P}<0.05$ and ${ }^{\wedge \wedge} \mathrm{P}<0.01$ vs. Ti particles. Ti, titanium; Bcl-2, B-cell lymphoma 2; Bax, Bcl-2-associated X protein.

detoxification $(40,41)$. It has been demonstrated that at high concentration, ROS might lead to severe injury to cells, which referred to the 'oxidative stress' (42-44). Aucubin has been reported that possessed the anti-oxidation activity $(45,46)$. Due to the ability of aucubin in the suppression of MC3T3-E1 cell apoptosis, it was arrestive that whether aucubin could affect the oxidative stress in MC3T3-E1 cells. Hence, we assessed the oxidative stress markers in MC3T3-E1 cells treated with aucubin, including ROS, MDA, LDH, SOD, and GPx. Obvious reductions of ROS, MDA, and LDH content were observed in the Ti particles-induced MC3T3-E1 cells treated with aucubin. Additionally, we also found that aucubin enhanced the activities of SOD and GPx in Ti particles-induced MC3T3-E1 cells. Thus, according to these results, it was confirmed that aucubin 
A

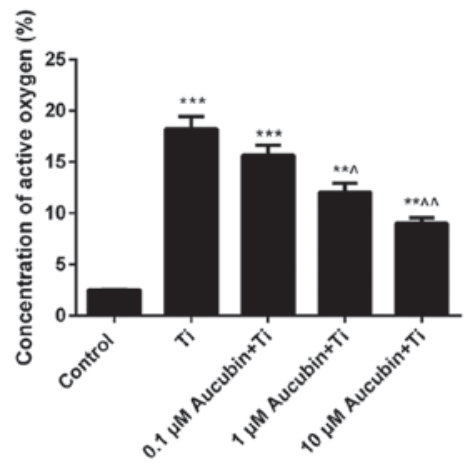

D

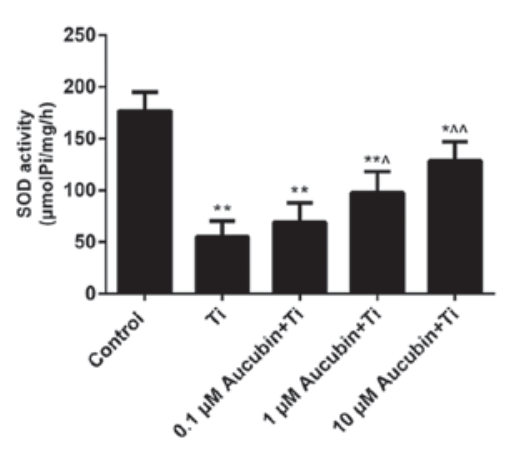

B

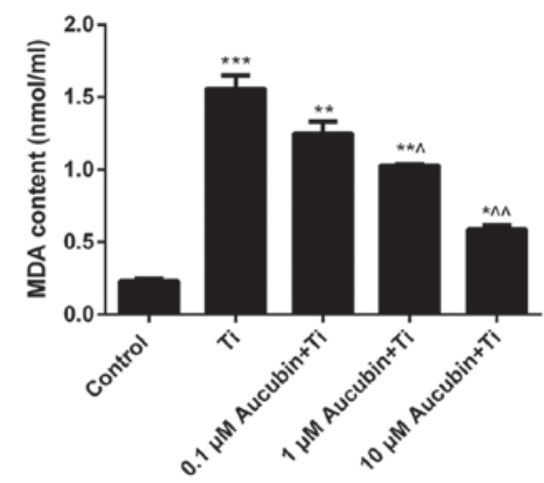

E

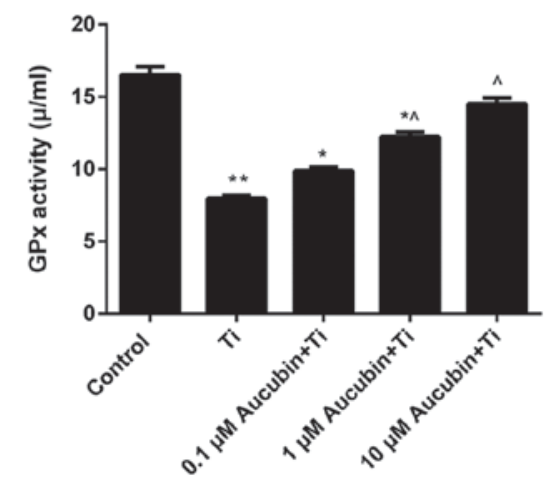

C

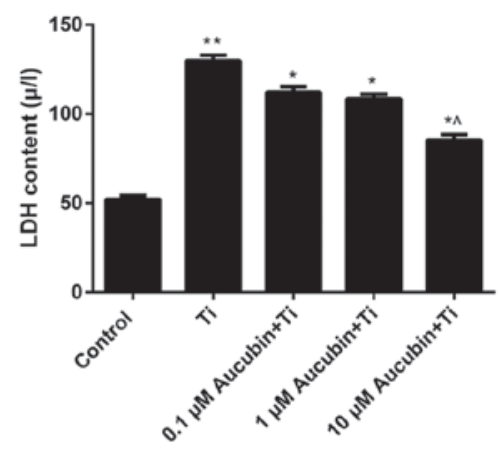

F

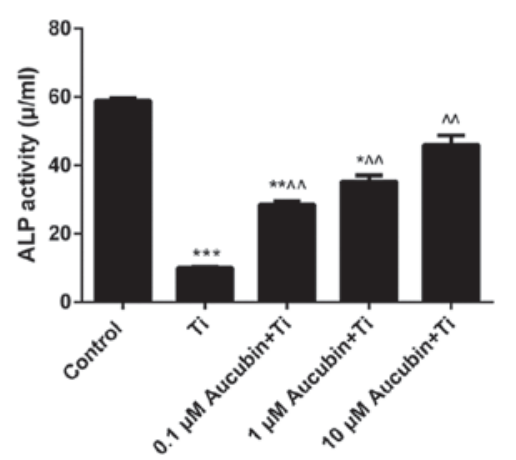

Figure 5. Aucubin reduces the stress. MC3T3-E1 cells were preprocessed with different concentration of aucubin $(0.1,1$ and $10 \mu \mathrm{M})$ for $6 \mathrm{~h}$ in advance, and then treated with Ti particles $(\leq 5 \mu \mathrm{m}, 0.1 \mathrm{wt} \%)$ for $12 \mathrm{~h}$. ELISA was performed to assess the levels of (A) ROS, (B) MDA, (C) LDH, (D) SOD and (E) GPx in MC3T3-E1 cells $(n=3)$. (F) pNPP colorimetry was carried out to assess the ALP activity in MC3T3-E1 cells. Data are presented as the mean \pm standard error mean $(\mathrm{n}=3) .{ }^{*} \mathrm{P}<0.05,{ }^{* *} \mathrm{P}<0.01$ and ${ }^{* * * *} \mathrm{P}<0.001$ vs. control; ${ }^{\wedge} \mathrm{P}<0.05$ and ${ }^{\wedge \wedge} \mathrm{P}<0.01$ vs Ti particles. Ti, titanium; ROS, reactive oxygen species; MDA, malondialdehyde; LDH, lactate dehydrogenase; SOD, superoxide dismutase; GPx, glutathione peroxidase; pNPP, para-nitrophenyl phosphate; ALP, alkaline phosphatase.

A

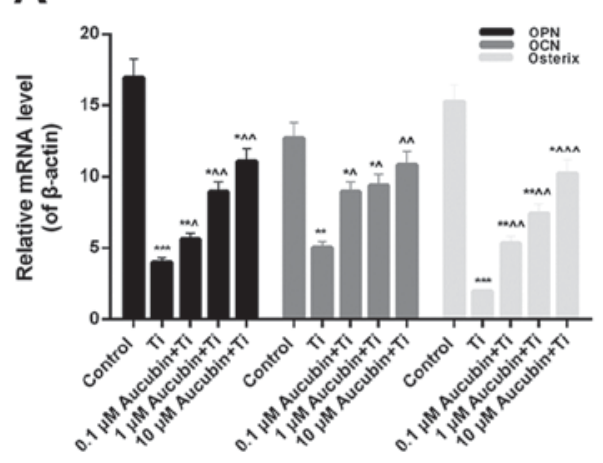

B

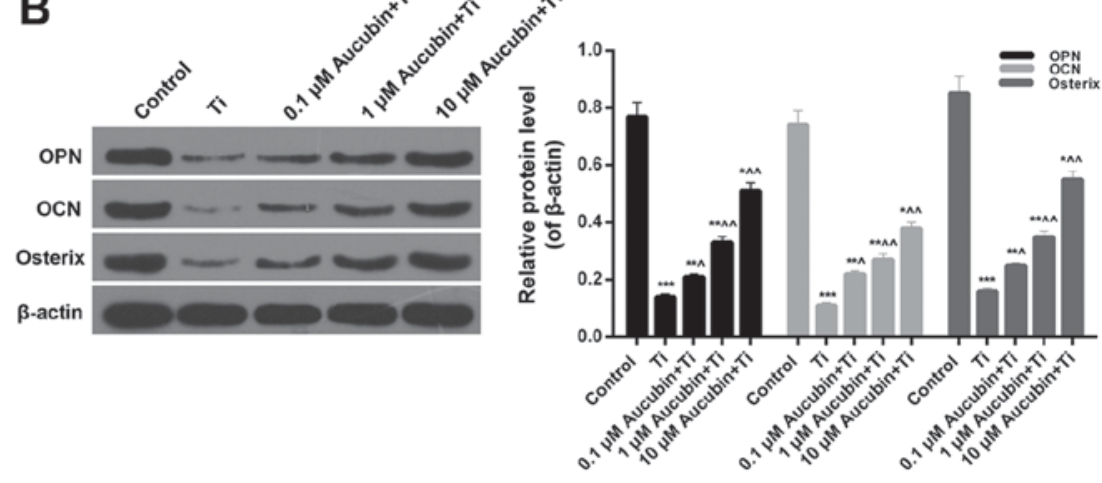

Figure 6. Aucubin facilitates osteogenesis. MC3T3-E1 cells were preprocessed with different concentrations of aucubin $(0.1,1 \mathrm{M}$ and $10 \mu \mathrm{M})$ for $6 \mathrm{~h}$ in advance, and then treated with Ti particles ( $\leq 5 \mu \mathrm{m}, 0.1 \mathrm{wt} \%$ ) for $12 \mathrm{~h}$. (A) Reverse transcription-quantitative polymerase chain reaction and (B) western blot assays were performed to measure the expression levels of OPN, OCN and Osterix in MC3T3-E1 cells. Data are presented as the mean \pm standard error mean (n=3). ${ }^{*} \mathrm{P}<0.05,{ }^{* *} \mathrm{P}<0.01$ and ${ }^{* * *} \mathrm{P}<0.001$ vs. control; ${ }^{\wedge} \mathrm{P}<0.05,{ }^{\wedge} \mathrm{P}<0.01$ and ${ }^{\wedge \wedge} \mathrm{P}<0.001$ vs. Ti particles. Ti, titanium; OPN, osteonectin; OCN, osteocalcin.

distinctly reduced the oxidative stress activated by Ti particles. At present, we proved that aucubin possessed the functions of suppressing the apoptosis and reducing the oxidative stress of $\mathrm{Ti}$ particles-induced MC3T3-E1 cells. Thus, the protective effects of aucubin on the MC3T3-E1 cells induced by Ti particles were demonstrated. Moreover, on account of MC3T3-E1 cells play an important role in the progression of osteogenesis. We thereby speculated that aucubin might impact the osteogenesis.

Based on the previous study (47), ALP, OPN, OCN, and Osterix were selected as osteoblast specific factors to evaluate the effect of aucubin in osteogenesis. In the current study, MC3T3-E1 cells acted as precursor osteoblasts, which could be gradually differentiated into osteoblasts in the specific medium. We found that the ALP activity, OPN, OCN, and Osterix expression in Ti particles-induced MC3T3-E1 cells was enhanced by aucubin. In consequence, it was proved that aucubin might facilitate osteogenesis through enhancing ALP activity and upregulating the expression levels of OPN, OCN, and Osterix in Ti particles-induced MC3T3-E1 cells. 

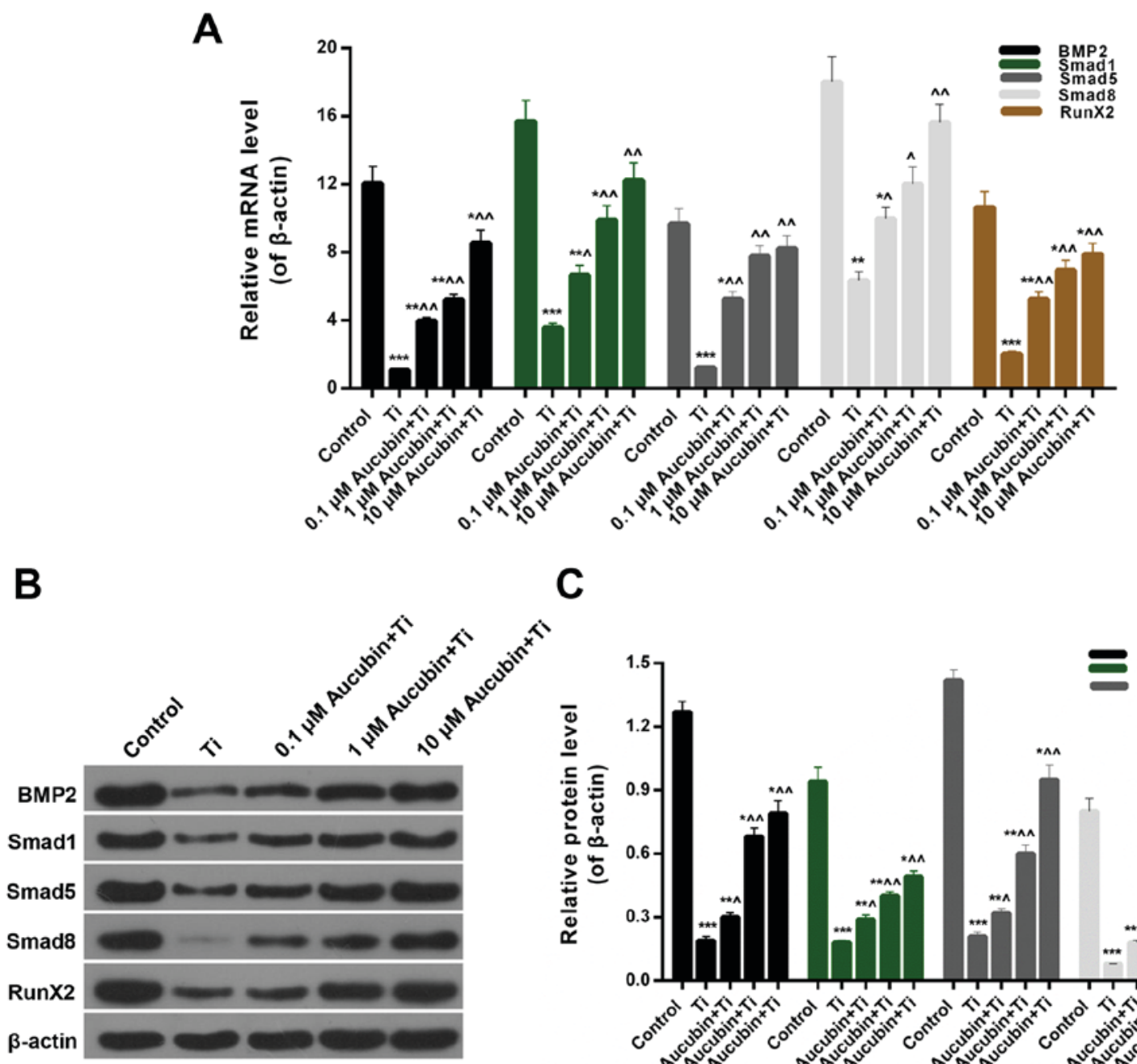

C

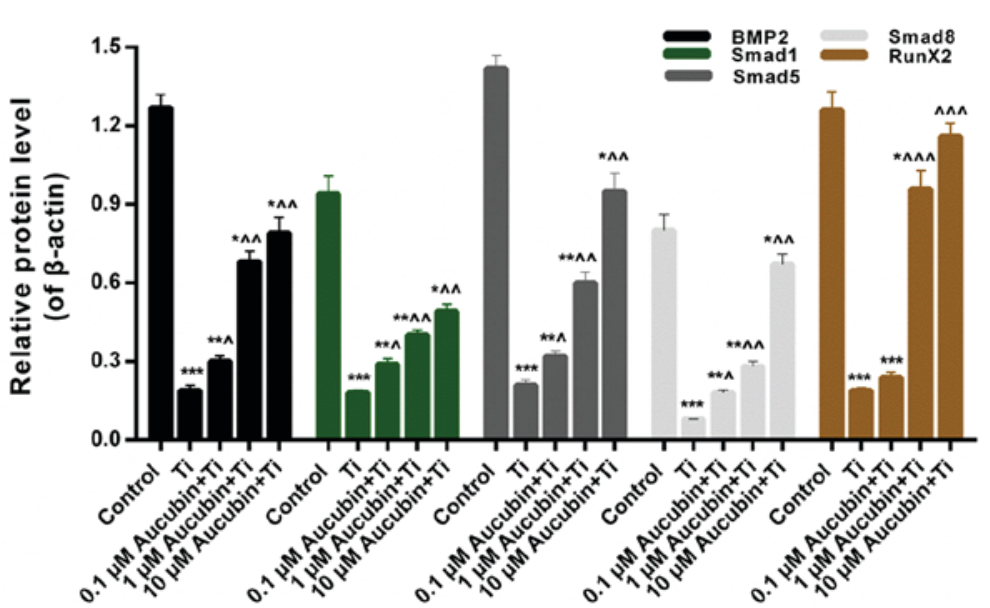

Figure 7. Aucubin affects the BMP2/Smads/RunX2 signaling pathway. MC3T3-E1 cells were preprocessed with different concentrations of aucubin (0.1, 1 and $10 \mu \mathrm{M})$ for $6 \mathrm{~h}$ in advance, and then treated with Ti particles $(\leq 5 \mu \mathrm{m}, 0.1 \mathrm{wt} \%)$ for $12 \mathrm{~h}$. (A) Reverse transcription-quantitative polymerase chain reaction and (B and C) western blot assays were performed to evaluate the expression levels of BMP2, Smad1/5/8, and RunX2 in MC3T3-E1 cells. Data are presented as the mean \pm standard error mean $(\mathrm{n}=3) .{ }^{*} \mathrm{P}<0.05,{ }^{* * *} \mathrm{P}<0.01$ and ${ }^{* * *} \mathrm{P}<0.001$ vs. control; ${ }^{\wedge} \mathrm{P}<0.05,{ }^{\wedge} \mathrm{P}<0.01$ and ${ }^{\wedge \wedge} \mathrm{P}<0.001$ vs. Ti particles. Ti, titanium; $\mathrm{BMP} 2$, bone morphogenetic protein 2; RunX2, runt related transcription factor 2.

Additionally, previous studies also have indicated that BMP2/Smads/RunX2 pathway might participate in the apoptosis and the process of osteogenesis $(48,49)$. Nevertheless, the accurate role and mechanism of aucubin in the regulation of BMP2/Smads/RunX2 pathway in osteoblasts apoptosis and osteogenesis is unclear. Thus, we further explored the probable mechanism of BMP2/Smads/RunX2 pathway in the suppression of osteoblasts apoptosis and promotion of osteogenesis. According to the western blot data, it was confirmed that the BMP2, Smad1/5/8, and RunX2 expression in Ti particles-induced MC3T3-E1 cells was strengthened by aucubin. Thus, we confirmed that aucubin could impact the BMP2/Smads/RunX2 pathway in Ti particles-induced MC3T3-E1 cells. All together, to the best of our knowledge, it was first proved that aucubin inhibited Ti particles-induced MC3T3-E1 cell apoptosis and facilitated osteogenesis by upregulating BMP2/Smads/RunX2 pathway.

In summary, our present work highlights that aucubin suppressed Ti particles-mediated apoptosis of MC3T3-E1 cells and facilitated osteogenesis through affecting
BMP2/Smads/RunX2 pathway. The findings of our research have crucial influence on the mechanisms of aucubin and osteoblasts. The potential effects of aucubin on the promotion of osteogenesis suggest that aucubin might be an effective target for osteogenesis promotion.

\section{Acknowledgements}

Not applicable.

\section{Funding}

This work was supported by Zhejiang Provincial Medical Science and Technology on General Item (grant nos. 2015KYA014 and 2017KY011).

\section{Availability of data and materials}

All data generated or analysed during this study are included in this published article. 


\section{Authors' contributions}

YC designed the experiments and wrote the article. $\mathrm{ZZ}$ conducted the cell culture and treatment sections, and analysed the function of Aucubin on the BMP2/Smads/RunX2 pathway. QX performed the MTT and flow cytometry assays to detect cell viability and apoptosis. SZ carried out ELISA and para-nitrophenyl phosphate colorimetry to evaluate the oxidative stress markers and alkaline phosphatase levels. YH was involved in the detection of the expression levels of apoptosis-associated factors.

\section{Ethics approval and consent to participate}

Not applicable.

\section{Consent for publication}

Not applicable.

\section{Competing interests}

The authors declare that they have no competing interests.

\section{References}

1. Caetano-Lopes J, Canhão H and Fonseca JE: Osteoblasts and bone formation. Acta Reumatol Port 32: 103-110, 2007.

2. Hadjidakis D and Androulakis II: Bone remodeling. Ann N Y Acad Sci 1092: 385-396, 2006

3. Ruff CB, Garofalo E and Holmes MA: Interpreting skeletal growth in the past from a functional and physiological perspective. Am J Phys Anthropol 150: 29-37, 2013.

4. Gowri AM, Kavitha G, Rajasundari M, Fathima SM, Kumar TM and Raj GD: Foetal stem cell derivation \& characterization for osteogenic lineage. Indian J Med Res 137: 308-315, 2013.

5. Gronthos S, Chen S, Wang CY, Robey PG and Shi S: Telomerase accelerates osteogenesis of bone marrow stromal stem cells by upregulation of CBFA1, osterix, and osteocalcin. J Bone Miner Res 18: 716-722, 2003.

6. Rajamannan NM: Oxidative-mechanical stress signals stem cell niche mediated Lrp5 osteogenesis in eNOS(-/-) null mice. J Cell Biochem 113: 1623-1634, 2012.

7. Wang F, Yin P, Lu Y, Zhou Z, Jiang C, Liu Y and Yu X: Cordycepin prevents oxidative stress-induced inhibition of osteogenesis. Oncotarget 6: 35496-35508, 2015.

8. Wang N, Wang F, Gao Y, Yin P, Pan C, Liu W, Zhou Z and Wang J: Curcumin protects human adipose-derived mesenchymal stem cells against oxidative stress-induced inhibition of osteogenesis J Pharmacol Sci 132: 192-200, 2016.

9. Galetz MC, Fleischmann EW, Konrad CH, Schuetz A and Glatzel U: Abrasion resistance of oxidized zirconium in comparison with CoCrMo and titanium nitride coatings for artificial knee joints. J Biomed Mater Res B Appl Biomater 93: 244-251, 2010.

10. Grübl A, Chiari C, Gruber M, Kaider A and Gottsauner-Wolf F: Cementless total hip arthroplasty with a tapered, rectangular titanium stem and a threaded cup: A minimum ten-year follow-up. J Bone Joint Surg Am 84-A: 425-431, 2002.

11. Lombardi AV Jr, Mallory TH, Vaughn BK and Drouillard P Aseptic loosening in total hip arthroplasty secondary to osteolysis induced by wear debris from titanium-alloy modular femoral heads. J Bone Joint Surg Am 71: 1337-1342, 1989.

12. Wang ML, Nesti LJ, Tuli R, Lazatin J, Danielson KG, Sharkey PF and Tuan RS: Titanium particles suppress expression of osteoblastic phenotype in human mesenchymal stem cells. J Orthop Res 20: 1175-1184, 2002.

13. Wang ML, Tuli R, Manner PA, Sharkey PF, Hall DJ and Tuan RS: Direct and indirect induction of apoptosis in human mesenchymal stem cells in response to titanium particles. J Orthop Res 21: 697-707, 2003.
14. Zreiqat H, Crotti TN, Howlett CR, Capone M, Markovic B and Haynes DR: Prosthetic particles modify the expression of bone-related proteins by human osteoblastic cells in vitro. Biomaterials 24: 337-346, 2003.

15. O'Connor DT, Choi MG, Kwon SY and Paul Sung KL: New insight into the mechanism of hip prosthesis loosening: Effect of titanium debris size on osteoblast function. J Orthop Res 22: 229-236, 2004.

16. Chenard KE, Teven CM, He TC and Reid RR: Bone morphogenetic proteins in craniofacial surgery: Current techniques, clinical experiences, and the future of personalized stem cell therapy. J Biomed Biotechnol 2012: 601549, 2012.

17. De Caestecker M and Meyrick B: Bone morphogenetic proteins, genetics and the pathophysiology of primary pulmonary hypertension. Respir Res 2: 193-197, 2001.

18. Axelrad TW and Einhorn TA: Bone morphogenetic proteins in orthopaedic surgery. Cytokine Growth Factor Rev 20: 481-488, 2009.

19. Conidi A, Cazzola S, Beets K, Coddens K, Collart C, Cornelis F, Cox L, Joke D, Dobreva MP, Dries R, et al: Few Smad proteins and many Smad-interacting proteins yield multiple functions and action modes in TGF//BMP signaling in vivo. Cytokine Growth Factor Rev 22: 287-300, 2011.

20. Simic P and Vukicevic S: Bone morphogenetic proteins: From developmental signals to tissue regeneration. Conference on bone morphogenetic proteins. EMBO Rep 8: 327-331, 2007.

21. Matsubara T, Kida K, Yamaguchi A, Hata K, Ichida F, Meguro H, Aburatani H, Nishimura R and Yoneda T: BMP2 regulates Osterix through Msx2 and Runx2 during osteoblast differentiation. J Biol Chem 283: 29119-29125, 2008

22. Nishimura R, Hata K, Matsubara T, Wakabayashi M and Yoneda T: Regulation of bone and cartilage development by network between BMP signalling and transcription factors. J Biochem 151: 247-254, 2012.

23. Derynck $R$ and Zhang YE: Smad-dependent and Smad-independent pathways in TGF-beta family signalling. Nature 425: 577-584, 2003.

24. Komori T: Regulation of osteoblast differentiation by Runx 2 . Adv Exp Med Biol 658: 43-49, 2010.

25. Saito T, Ogawa M, Hata Y and Bessho K: Acceleration effect of human recombinant bone morphogenetic protein-2 on differentiation of human pulp cells into odontoblasts. J Endod 30: 205-208, 2004

26. Chang LM, Yun HS, Kim YS and Ahn JW: Aucubin: Potential antidote for alpha-amanitin poisoning. J Toxicol Clin Toxicol 22: 77-85, 1984.

27. Li Y, Sato T, Metori K, Koike K, Che QM and Takahashi S: The promoting effects of geniposidic acid and aucubin in Eucommia ulmoides Oliver leaves on collagen synthesis. Biol Pharm Bull 21: 1306-1310, 1998.

28. Chang IM: Liver-protective activities of aucubin derived from traditional oriental medicine. Res Commun Mol Pathol Pharmacol 102: 189-204, 1998.

29. Chang IM, Ryu JC, Park YC, Yun HS and Yang KH: Protective activities of aucubin against carbon tetrachloride-induced liver damage in mice. Drug Chem Toxicol 6: 443-453, 1983.

30. Jin L, Xue HY, Jin LJ, Li SY and Xu YP: Antioxidant and pancreas-protective effect of aucubin on rats with streptozotocin-induced diabetes. Eur J Pharmacol 582: 162-167, 2008.

31. Xue HY, Gao GZ, Lin QY, Jin LJ and Xu YP: Protective effects of aucubin on $\mathrm{H}_{2} \mathrm{O}_{2}$-induced apoptosis in $\mathrm{PC} 12$ cells. Phytothe Res 26: 369-374, 2012

32. Xue H, Jin L, Jin L, Zhang P, Li D, Xia Y, Lu Y and Xu Y: Neuroprotection of aucubin in primary diabetic encephalopathy. Sci China C Life Sci 51: 495-502, 2008.

33. Ha H, Ho J, Shin S, Kim H, Koo S, Kim IH and Kim C: Effects of Eucommiae Cortex on osteoblast-like cell proliferation and osteoclast inhibition. Arch Pharm Res 26: 929-936, 2003.

34. Sudo H, Kodama HA, Amagai Y, Yamamoto S and Kasai S: In vitro differentiation and calcification in a new clonal osteogenic cell line derived from newborn mouse calvaria. J Cell Biol 96: 191-198, 1983.

35. Czekanska EM, Stoddart MJ, Richards RG and Hayes JS: In search of an osteoblast cell model for in vitro research. Eur Cell Mater 24: 1-17, 2012.

36. Chen G, Deng $\mathrm{C}$ and Li YP: TGF- $\beta$ and BMP signaling in osteoblast differentiation and bone formation. Int J Biol Sci 8: 272-288, 2012.

37. Aubin JE and Turksen K: Monoclonal antibodies as tools for studying the osteoblast lineage. Microsc Res Tech 33: 128-140, 1996. 
38. Matsumoto A: The effect of cell environment on osteoblastic function. Nihon Yakurigaku Zasshi 105: 273-283, 1995 (In Japanese).

39. Lin J, Fan YJ, Mehl C, Zhu JJ, Chen H, Jin LY, Xu JH and Wang HM: Eucommia ulmoides Oliv. antagonizes $\mathrm{H} 2 \mathrm{O} 2$-induced rat osteoblastic MC3T3-E1 apoptosis by inhibiting expressions of caspases 3, 6, 7, and 9. J Zhejiang Univ Sci B 12: 47-54, 2011.

40. Akopova OV, Kolchinskaya LI, Nosar VI, Bouryi VA Mankovska IN and Sagach VF: Cytochrome $\mathrm{C}$ as an amplifier of ROS release in mitochondria. Fiziol Zh 58: 3-12, 2012.

41. Marchi S, Giorgi C, Suski JM, Agnoletto C, Bononi A, Bonora M, De Marchi E, Missiroli S, Patergnani S, Poletti F, et al: Mitochondria-ros crosstalk in the control of cell death and aging. J Signal Transduct 2012: 329635, 2012.

42. Cadenas E and Davies KJ: Mitochondrial free radical generation, oxidative stress, and aging. Free Radic Biol Med 29: 222-230, 2000

43. Halliwell B and Gutteridge JM: Role of free radicals and catalytic metal ions in human disease: An overview. Methods Enzymol 186: 1-85, 1990.

44. Lenaz G, Bovina C, Formiggini G and Parenti Castelli G: Mitochondria, oxidative stress, and antioxidant defences. Acta Biochim Pol 46: 1-21, 1999.

45. Ho JN, Lee YH, Lee YD, Jun WJ, Kim HK, Hong BS, Shin DH and Cho HY: Inhibitory effect of Aucubin isolated from Eucommia ulmoides against UVB-induced matrix metalloproteinase-1 production in human skin fibroblasts. Biosci Biotechnol Biochem 69: 2227-2231, 2005.
46. Ho JN, Lee YH, Park JS, Jun WJ, Kim HK, Hong BS, Shin DH and Cho HY: Protective effects of aucubin isolated from Eucommia ulmoides against UVB-induced oxidative stress in human skin fibroblasts. Biol Pharm Bull 28: 1244-1248, 2005.

47. Park KW, Waki H, Kim WK, Davies BS, Young SG, Parhami F and Tontonoz P: The small molecule phenamil induces osteoblast differentiation and mineralization. Mol Cell Biol 29: 3905-3914, 2009.

48. Eliseev RA, Dong YF, Sampson E, Zuscik MJ, Schwarz EM, O'Keefe RJ, Rosier RN and Drissi MH: Runx2-mediated activation of the Bax gene increases osteosarcoma cell sensitivity to apoptosis. Oncogene 27: 3605-3614, 2008

49. Gaur T, Lengner CJ, Hovhannisyan H, Bhat RA, Bodine PV, Komm BS, Javed A, van Wijnen AJ, Stein JL, Stein GS and Lian JB: Canonical WNT signaling promotes osteogenesis by directly stimulating Runx2 gene expression. J Biol Chem 280: 33132-33140, 2005.

This work is licensed under a Creative Commons Attribution-NonCommercial-NoDerivatives 4.0 International (CC BY-NC-ND 4.0) License. 